\title{
INCIDENTAL PARASITIC INFECTIONS IN SURGICALLY REMOVED APPENDICES: A RETROSPECTIVE ANALYSIS
}

\author{
By \\ DINA A. ZAGHLOOL ${ }^{1,2}$, AMAL A. HASSAN ${ }^{2,3}$, MONA A. AHMED $^{4,5}$,
And HANI S. FAIDAH
}

Department of Medical Parasitology, Faculty of Medicine, Assuit University, Assuit, Egypt $^{1}$, Laboratory and Blood Bank Department, Al-Noor Specialist Hospital, Makkah, Saudi Arabia $^{2}$, Department of Pathology, Faculty of Medicine, Al-Azhar University, Cairo, Egypt ${ }^{3}$, Department of Medical Parasitology, Faculty of Medicine, Ain Shams University, Cairo, Egypt ${ }^{4}$, Department of Laboratory and Blood Bank, King Abdullah Medical City, Makkah ${ }^{5}$, and Department of medical and molecular microbiology. Faculty of Medicine, Umm AL-Qura University ${ }^{6}$, Saudi Arabia

\begin{abstract}
Numerous parasitic infections can cause inflammation of the appendix and can mimic appendicitis clinically. The diagnosis is generally achieved only after surgery. However early diagnosis through stool examination may prevent life-threatening complications. This study investigated the presence of parasitic infections in surgically removed appendices as an etiology of acute appendicitis. A retrospective study included patients who had undergone surgery for acute appendicitis over a period of three years from Jan 2012 to Dec 2014. Demographic data, laboratory investigations, operative data and pathological findings, presence and type of parasites were retrieved.

The results showed that out of 1536 patients with appendectomy done, $938(61.1 \%)$ were males and 598 (38.9\%) were females. Parasitic infection was demonstrated only in $0.4 \%$ (6 patients). Mean average age of these patients was 12 years. Enterobius vermicularis was present in 4 patients (66\% of the parasitic affection) and Schistosoma mansoni in 2 patients (34\% of the parasitic affection). Other etiologies were acute suppurative appendicitis $(94.1 \%)$, chronic appendicitis $(3.1 \%)$, tumors $(0.3 \%)$, tuberculosis $(0.2 \%)$ and actinomycosis $(0.1 \%)$. Appendix was found normal in $2 \%$ of patients underwent appendectomy.
\end{abstract}

Key words: Acute appendicitis, Intestinal parasitic infection, Enterobius vermicularis, Schistosoma mansoni

\section{Introduction}

Appendicitis is the commonest abdominal surgical emergency (Humes and Simpson, 2006). The etiologic factors and incidence of appendicitis differ regionally but luminal obstruction is considered the most critical factor (Akbulut et al, 2011). It is primarily a disease of adolescents and young adults with a peak incidence in the second and third decades of life (Flasar and Gold-berg, 2006).

Acute appendicitis is probably multifactorial (Karatepe et al, 2009). Parasitic infec-tions stood for appendicitis rare etiology (Yabanoğlu et al, 2014). The overwhelming majority of parasites of appendix were not associated with acute inflammations (Yildirim et al, 2005). The parasites in appendix may cause appendiceal colic even without eliciting an acute inflammation due to lumen obstruction. Parasites causing an appendiceal colic could not be differentiated from the usual acute appendicitis right lower quadrant. Clinical and laboratory findings of an infection are generally observed as the intestinal system is already involved by the parasites (Aydin, 2007). Most prominent parasitic agents concerned with appendicitis were Enterobius vermicularis, Schistosoma spp, Taenia spp. and Ascaris lumbricoides (Sah and Bhadani, 2006). Enterobius vermicularis infected gastrointestinal tract approximately in $4 \%$ to $28 \%$ children worldwide (Adorisio et al, 2015), with an incidence in patients with appendicitis symptoms ranged from $0.2-41.8 \%$ (Arca et al, 2004). E. vermicularis was 
endemic in Saudi Arabia, especially in rural areas (Zakaria et al, 2013). The relation between E. vermicularis and acute appendicitis was a controversy concerning its etiology in appendicitis (Gialamas et al, 2012).

This study evaluated the role of parasitic infections in acute appendicitis and to detect the incidence of parasitic diseases in appendectomy specimens.

\section{Patients, Materials and Methods}

Demographic and histopathological findings, parasites and patients underwent simple appendectomy at Al-Noor Specialist Hospital, Makah, from January 2012 to December 2014 were retrieved from the hospital's electronic record system and analyzed. Samples obtained during other surgical procedu-res were excluded. Acute appendicitis was diagnosed by history, clinical exam, elevated white blood cell count, and ultrasonography.

Formalin-fixed and paraffin-embedded appendicular specimens were prepared. Two sections $5 \mathrm{u}$ was cut, one stained with hematoxylin and eosin for histopathological examination (Dalimi and Khoshzaban, 1993), and second one was mounted on positive charged slide and immune-stained by mouse monoclonal antibodies against chromogranin
$\mathrm{A}$, in cases of neuroendocrine tumors. Immunohistochemistry (IHC) was performed on paraffin sections using Ultraview DAB detection kit on Ventana Bench Mark XT staining system (Ventana Medical Systems, Tucson, Arizona, USA). Immunohistochemistry for Chromogranin A was performed using ventana antibody with cytoplasmic staining. A lesion was considered positive for a marker when $10 \%$ or more cells showed characteristic reactivity for the immune-stain. The acute appendicitis diagnosis was suspected when a polymerphonuclear neutrophil infiltrate seen in the mucosa or deep layers. All appendices were examined by histopathology department and parasites were reevaluated by expert parasitologists.

Statistical analysis: Data was done using SPSS software (version 15.0, SPSS Inc., Chicago, IL, USA). Frequencies were found for all variables and cross-tabulation was used to compare frequencies in groups.

\section{Results}

A total of 938/1536 appendices (61.1\%) were males and (38.9) were females with ages of $22.24 \pm 12.880$. Appendicitis histopathological was classified as acute suppurative, chronic, normal, parasitic, T.B. and actinomycosis.

Table 1: Distribution of histopathological types of appendices in patients

\begin{tabular}{|l|c|c|}
\hline Histopathological type & Frequency & Percent \\
\hline Acute suppurative appendicitis & 1445 & $94.1 \%$ \\
\hline Chronic appendicitis & 47 & $3.1 \%$ \\
\hline Normal Appendix & 30 & $2.0 \%$ \\
\hline Parasitic & 6 & $0.4 \%$ \\
\hline Tumor & 4 & $0.3 \%$ \\
\hline T.B & 3 & $0.2 \%$ \\
\hline Actinomycosis & 1 & $0.1 \%$ \\
\hline Total & 1536 & $100.0 \%$ \\
\hline
\end{tabular}

Table 2: Distribution of histopathological types of appendices according to ages.

\begin{tabular}{|l|c|c|c|c|c|c|}
\hline \multirow{2}{*}{ Histopathological type } & \multicolumn{7}{|c|}{ Age group in years } & \multirow{2}{*}{ Total } \\
\cline { 2 - 6 } & $0-14$ & $15-29$ & $30-44$ & $45-59$ & $>60$ & \\
\hline Acute supportive appendicitis & 483 & 627 & 230 & 77 & 28 & 1445 \\
\hline Chronic appendicitis & 10 & 34 & 2 & 1 & 0 & 47 \\
\hline Normal Appendix & 12 & 12 & 3 & 2 & 1 & 30 \\
\hline Parasitic & 3 & 2 & 1 & 0 & 0 & 6 \\
\hline Tumor & 1 & 2 & 1 & 0 & 0 & 4 \\
\hline T.B & 0 & 2 & 1 & 0 & 0 & 3 \\
\hline Actinomycosis & 0 & 1 & 0 & 0 & 0 & 1 \\
\hline Total & 509 & 680 & 238 & 80 & 29 & 1536 \\
\hline
\end{tabular}


Table 3: Distribution of histopathological types of appendices according to sex of patients

\begin{tabular}{|l|c|c|c|c|c|c|}
\hline \multirow{2}{*}{\multicolumn{1}{|c|}{ Histopathological type }} & \multicolumn{6}{|c|}{ Sex of patient } \\
\cline { 2 - 7 } & \multicolumn{3}{|c|}{ Count } & \multicolumn{3}{c|}{ Percent } \\
\cline { 2 - 7 } & Female & Male & Total & Female & Male & Total \\
\hline Acute suppurative appendicitis & 549 & 896 & 1445 & $35.7 \%$ & $58.3 \%$ & $94.1 \%$ \\
\hline Chronic appendicitis & 23 & 24 & 47 & $1.5 \%$ & $1.6 \%$ & $3.1 \%$ \\
\hline Normal Appendix & 17 & 13 & 30 & $1.1 \%$ & $0.8 \%$ & $2.0 \%$ \\
\hline Parasitic & 3 & 3 & 6 & $0.2 \%$ & $0.2 \%$ & $0.4 \%$ \\
\hline Tumor & 2 & 2 & 4 & $0.1 \%$ & $0.1 \%$ & $0.3 \%$ \\
\hline T.B & 3 & 0 & 3 & $0.2 \%$ & $0.0 \%$ & $0.2 \%$ \\
\hline Actinomycosis & 1 & 0 & 1 & $0.1 \%$ & $0.0 \%$ & $0.1 \%$ \\
\hline Total & 598 & 938 & 1536 & $38.9 \%$ & $61.1 \%$ & $100.0 \%$ \\
\hline
\end{tabular}

Normal findings in $30(2 \%)$ patients were prevalent histologically. Parasitic infections were seen in $6(0.4 \%)$ patients, 3 males and 3 females. E. vermicularis found in four appendices $(0.26 \%)$, and $S$. mansoni in two cases $(0.14 \%)$. Ages of patients with parasitic appendices ranged from 4 to 30 with a median of 12 years.

Table 4: Distribution of parasitic infections in resected appendices appendices according to ages and sexes

\begin{tabular}{|c|l|c|c|c|c|}
\hline Patient No & \multicolumn{1}{|c|}{ Parasite } & Age & Sex & Acute Inflammation & USG \\
\hline 1 & S. mansoni & 30 & Male & Negative & NA \\
\hline 2 & E. vermicularis & 13 & Female & Positive & NA \\
\hline 3 & E. vermicularis & 22 & Female & Positive & AA \\
\hline 4 & S. mansoni & 22 & Male & Negative & AA \\
\hline 5 & E. vermicularis & 8 & Male & Positive & NA \\
\hline 6 & E. vermicularis & 4 & Female & Positive & NA \\
\hline
\end{tabular}

USG: Ultrasonography scans, AA: acute appendicitis, NA: normal appendix

Table 5: Distribution of tumors in resected appendices in relation to age and sex in patients

\begin{tabular}{|c|c|c|c|c|l|}
\hline Patient No & Age & Sex & Acute Inflammation & USG & Tumor type \\
\hline 1 & 19 & Female & Negative & NA & Neuroendocrine \\
\hline 2 & 13 & Male & Positive & NA & Neuroendocrine \\
\hline 3 & 15 & Male & Negative & NA & Carcinoid Tumor \\
\hline 4 & 33 & Female & Negative & NA & Mucinous Cystadenoma \\
\hline
\end{tabular}

Appendicular tumor in $4(0.3 \%)$ patients, 2 male and 2 female, Neuroendocrine tumor in two appendices and carcinoid tumor in one appendix and mucinous cystadenoma in one appendix.

Ages of patients with tumor on appendix ranged from 13 to 33 with a median of 23 years

\section{Discussion}

In the present study, six parasitic appendices out of $1536(0.4 \%)$ appendectomies were recorded. Other etiologies were acute suppurative appendicitis $(94.1 \%)$, chronic appendicitis $(3.1 \%)$, tumors $(0.3 \%)$, tuberculosis $(0.2 \%)$ and actinomycosis $(0.1 \%)$, but normal in patients $(2 \%)$ underwent appendectomy. Incidence of parasitic infection was low, but higher than other causes as tumors, tuberculosis and/or actinomycosis. Shrestha et al. (2012) detected acute appendicitis in $(66.4 \%)$, chronic appendicitis in $(2.5 \%)$, carcinoid tumor in $(0.1 \%)$ \& parasites in $(0.2 \%)$ but negative appendectomy in (10.8\%). Also, Emre et al (2013) reported acute appendicitis in (86.9\%), lymphoid hyperplasia in $(5.3 \%)$, fibrous obliteration in $(4.8 \%)$, gra- nulomatous inflammation in $(0.5 \%)$ and unusual histopathologic findings in $(7.5 \%)$ including carcinoid tumor in $(0.9 \%)$ and parasitic infections in $(0.77 \%)$.

In the present study, parasites were equal in males and females, similar to Aydin (2007) but males were higher with Yabanoğlu et al. (2014) and vice versa with Shrestha et al. (2012). Mean age of patients with parasitic infections was 12 years (4 to 30 ), this was young ages patients were the risky group especially with $E$. vermicularis (Gialamas et al, 2012).

In the present study, low parasitic appendix was $0.4 \%$, which more or less coincided with 0.05-3\% reported (da Silva et al, 2007; Karatepe et al, 2009; Akbulut et al, 2011; Yabanoğlu et al, 2014). However, higher 
percentages were $7 \%$ in Venezuelan pediatric patients (Dorfman et al. 2003) and 75\% in different Nigerian populations (Okolie et al, 2008).

The present study, the commonest parasite was E. vermicularis $(0.26 \%)$ of total appendices cases with an overall of $66 \%$, followed by $S$. mansoni $(0.14 \%)$ of total appendices cases with an overall of 33\%. Zakaria et al. (2013) among Saudi pediatric patients reported (2.8\%) E. vermicularis, which proved to be the commonest worm found in appendix $(0.2 \%$ to $41.8 \%)$ worldwide (Arca et al, 2004).

In the present study, appendicitis due to $E$. vermicularis infection was diagnosed in the lumen of acutely inflamed appendix as eggs and remnant mostly of worm (Fig. 1A \& B). In another case, the musculosa of the appendix did not show inflammatory reaction, but lumen showed Enterobius worm (Fig.1C). Another specimen showed abundant luminal exudates with focal mucosal ulceration and appendicular wall was invaded by an adult worm (Fig.1D). These variations in the histopathological changes went with the assumption that $E$. vermicularis in the appendix can produce symptoms of acute appendicitis independent of histological changes. E. vermicularis in appendix might cause no tissue reaction or pathologic changes ranging from lymphoid hyperplasia to obstructive effect to life-threatening acute inflammations, and might also invade the appendix wall causing inflammation (Schou-Jensen, 2014). The luminal obstruction may cause an increase in the intraluminal pressure which impairs the circulation of the appendix wall and mucosal damage may cause bacterial invasion, inflammation, sepsis and finally necrosis and perforation (Engin et al, 2010).

The second common parasite detected in the present study was S. mansoni $0.14 \%$ lower compared to $1.3 \%$ (Abu-Eshy et al, 1995) \& 1.4\% (Zakaria et al, 2013) in Saudi Arabia but identical with $0.11 \%$ in Turkey (Karatepe et al, 2009). Schistosomiasis was considered a rare cause of acute appendicitis
(Cox and Yates, 2010; Ladu, 2014). In contrast, Botes et al. (2015) in African endemic areas schistosomiasis in appendicitis was $<10 \%$. This difference might be attributed to epidemiological factors and human habitats.

In the present study, schistosomal appendicitis was detected (Fig.1E \& F) in the form of polypoid caecal tissues, studded with multiple eosinophilic granulomas around living eggs. Pericolic lymph nodes revealed reactive hyperplasia findings consistent with a previous study (Adisa et al, 2009). These explained the role of schistosomiasis in the appendicitis pathogenesis as granulomatous acute appendicitis (Satti et al, 1987). In Saudi Arabia, schistosomal appendicitis highlighted submucosal fibosis as a commonest histological finding (Meshikhes et al, 1999), and this clarified mechanism for the schistosomal appendicitis, obstructive acute appendicitis. The long-standing inflammation and fibrosis around dead eggs, led to obstruction of the appendiceal lumen and later secondary bacterial appendicitis (Vilela Desposorio and Cusma Quintana, 2015).

In the present study, in appendix specimens containing E. vermicularis, 3 (75\%) exhibited normal appendix tissue and or ultrasonography, one (25\%) acute non-complicated appendicitis. Clinically, it could be difficult to differentiate between parasitic appendicitis and others non-inflamed appendicitis, except at surgery. Also, the present study that detected parasitic infection was more or less in histopathological normal appendix, which agreed with Zakaria (2012).

In the present study, neither Ascaris lumbricoides nor Entamoeba histolytica was detected as parasites within the appendix. In Egypt, Hedya et al. (2012) reported four cases $(1.59 \%)$ of E. vermicularis, Ascaris lumbricoides two cases $(0.79 \%), S$. mansoni eggs in three cases $(1.19 \%)$, and parasitic amebiasis in two cases $(0.79 \%)$.

Generally, the intestinal parasites cause considerable problems worldwide (Sadeghi et $a l, 2015)$. They may cause symptoms mi- 
micking acute appendicitis; with controversial etiology (Wiwanitkit, 2014). Besides, parasites detected within surgically removed appendices were rare (Karatepe et al, 2009; Yabanoğlu et al, 2014). The commonest cause of acute appendicitis was occlusion of the appendix lumen, with obstructing agent usually fecal stasis and fecaliths, lymphoid hyperplasia, vegetable matter and then fruit seeds, insisted barium from the previous radiographic studies, intestinal parasites, and tumors (Prystowsky et al, 2005).

\section{Conclusion}

Parasitic infections were detected at a very low rate as $0.4 \%$ of total appendectomy specimens. In all these cases diagnosis was made only after surgery. Intestinal parasitic infections may produce a clinical picture resembling appendicitis but rarely causes acute appendicitis. The early diagnosis and treatment could prevent unnecessary appendectomies and may prevent life-threatening complications.

No doubt, the close friends and family members may be examined for the parasitic infection and carrier state. Still the question; whether the parasite existence in appendix is incidental or a factor of the inflammation initiation need to be thoroughly investigated.

\section{References}

Abu-Eshy, SA, Malik, GM, Khan, AR, Khan, GM, Al-Shehri, MY, 1995: Schistosomal appendicitis. Ann. Saudi Med.15:347-9.

Adisa, A01, Omonisi, AE, Osasan, SA, Alatise, OI, 2009: Clinicopathological review of schistosomal appendicitis in south western Nigeria. Trop. Gastroenterol. 30:230-2.

Adorisio, O, De Peppo, F, Rivosecchi, M, Silveri, M, 2015: Enterobius vermicularis as a cause of intestinal occlusion: How to avoid unnecessary surgery. Pediatr. Emerg. Care Jul 20. [Epub ahead of print]

Akbulut, S, Tas, M, Sogutcu, N, Arikanoglu, Z, Basbug, M, et al, 2011: Unusual histopathological findings in appendectomy specimens: a retrospective analysis and literature review. World J. Gastroenterol. 17:1961-70.

Arca, MJ, Gates, RL, Groner, JI, Hammond, S, Caniano, DA, 2004: Clinical manifestations of appendiceal pinworms in children: an institu- tional experience and a review of the literature. Pediatr. Surg. Int. 20, 5:372-5.

Aydin, O, 2007: Incidental parasitic infestations in surgically removed appendices: a retrospecttive analysis. Diag. Pathol. 2:16. doi:10.1186/ 1746-1596-2-16

Botes, SN, Ibirogba, SB, McCallum, AD, Kahn, D, 2015: Schistosoma prevalence in appendicitis. World J. Surg. 39, 5:1080-3.

Cheesbrough, M, 1998: District Laboratory Practice in Tropical Countries, Part 1- Cambridge University Press.

Cox, N, Yates, P, 2010: Schistosomiasis: a rare cause of acute appendicitis. J. Surg. Case Rep. 4: 4-6.

da Silva, DF, da Silva, RJ, da Silva, MG, Sartorelli, AC, Rodrigues, MA, 2007: Parasitic infection of the appendix as a cause of acute appendicitis. Parasitol. Res. 102:99-102

Dalimi, A, Khoshzaban, F, 1993: Comparative study of two methods for the diagnosis of Enterobius vermicularis in the appendix. J. Helminthol. 67, 1:85-6.

Dorfman, S, Cardozo, J, Dorfman, D, Del Villar, A, 2003: The role of parasites in acute appendicitis of pediatric patients. Invest Clin. 44, 4:337-40.

Emre, A, Akbulut, S, Bozdag, Z, Yilmaz, M, Kanlioz, M, et al, 2013: Routine histopathologic examination of appendectomy specimens: retrospective analysis of 1255 patients. Int. Surg. 98, 4:354-62.

Engin, O, Calik, S, Calik, B, Yildirim, M, Coskun, G, 2010: Parasitic appendicitis from past to present in Turkey. Iranian J. Parasitol. 5, 3:5763.

Engin, O, Muratli, A, Uca, AD, Tekin, V, Calik, B, et al, 2012: The importance of fecaliths in the aetiology of acute appendicitis. Chirurgia (Bucur).107:756-60.

Flasar, MH, Goldberg, E, 2006: Acute abdominal pain. Med. Clin. North Am. 90, 3:481-503.

Gialamas, E, Papavramidis, T, Michalopoulos, N, Karayannopoulou, G, Cheva, A, et al, 2012: Enterobius vermicularis: a rare cause of appendicitis. Turk. Parazitol. Derg. 36, 1:37-40.

Hedya, MS, Nasr, MM, Ezzat, H, Hamdy, H, Hassan, A, et al, 2012: Histopathological findings in appendectomy specimens: a retrospective clinico-pathological analysis. J. Egypt. Soc. Parasitol. 42, 1:157-64. 
Karatepe, O, Adas, G, Tukenmez, M, Battal, M, Altiok, M, et al, 2009: Parasitic infection as cause of acute appendicitis. J. Chir. 30, 10:426-8 Ladu, R, 2014: Schistosomiasis as a rare cause of recurrent acute appendicitis - A case report. Int. J. Surg. Case Rep. 5, 3:159-60.

Madhukar, KP, Verma, R, Sayed, Z, Vira, L, 2014: Acute appendicitis secondary to Enterobius vermicularis infestation in a young female: a case report. JEMDS 3, 19:5219-23.

Meshikhes, AW, Chandrashekar, CJ, Al-Daolah, Q, Al-Saif, O, Al-Joaib, AS, et al, 1999: Schistosomal appendicitis in the Eastern Province of Saudi Arabia: A clinicopathological study. Ann. Saudi Med. 19:12-4.

Prystowsky, JB, Pugh, CM, Nagle, AP, 2005: Current problems in surgery. Appendicitis Curr. Probl. Surg. 42: 688-702.

Sadeghi, H, Bakht, M, Saghafi, H, Shahsavari, T, 2015: Prevalence of intestinal parasites in a population in Eghbalieh city from Qazvin Pro-vince, Iran. J. Parasit. Dis. 39, 2:126-9

Sah, SP, Bhadani, PP, 2006: Enterobius vermicularis causing symptoms of appendicitis in Nepal. Trop. Doct. 36:160-2.

Satti, MB, Tamimi, DM, Al Sohaibani, MO, Al Quorain, A, 1987: Appendicular schistosemiasis: a cause of clinical acute appendicitis? J. Clin. Pathol. 40: 424-8.

Schou-Jensen, K1, Antipina, EN, Brisling, S K, Azawi, N, 2014: Perforation of the appendix and observation of Enterobius vermicularis. Ugeskr Laeger. 15, 176:51-9.

Shrestha, R1, Ranabhat, SR1, Tiwari, M1, 2012: Histopathologic analysis of appendectomy Specimens. J. Pathol. Nepal. 2:215-9

Sodergren, MH, Jethwa, P, Wilkinson, S, Kerwat, R, 2009: Presenting features of Enterobius vermicularis in the vermiform appendix. Scand. J. Gastroenterol. 44:457-61.

Vilela Desposorio, CD, Cusma Quintana, TN, 2015: Association between appendiceal obstruction and the morphological type of acute appendicitis. Rev. Gastroenterol. Peru 35, 1:32-7.

Wiwanitkit, V, 2014: Parasitic appendicitis. Oman Med. J. 29, 1:76 -82..

Yabanoğlu, H, Aytaç, HÖ, Türk, E, Karagülle, E, Calışkan, K, et al, 2014: Parasitic infections of the appendix as a cause of appendectomy in adult patients. Turk. Parazitol. Derg. 38: 12-6.

Yıldırım S, Nursal TZ, Tarım A, Kayaselcuk F, Noyan T, 2005: A rare cause of acute appendicitis: parasitic infection. Scand. J. Infect. Dis. 37:757-9.

Zakaria, O, 2012: The controversy of parasitic infection in pediatric appendicitis: A retrospective analysis. Ann. Pediatr. Surg. 8, 1:15-8.

Zakaria, OM, Zakaria, HM, Daoud, MY, Al Wadaani, H, Al Buali, W, et al, 2013: Parasitic infection in pediatric and adolescent appendicitis: A local experience. Oman Med J. 28, 2:92-6.

\section{Explanations of figures}

Fig. 1: A and B: Luman contain Enterobius eggs and helminthes remnant mostly of Enterobius. C: Adult of E. vermicularis in appendix lumen, D: Acute appendicitis with enterobiasis, in appendix mucosa. E and F: Polypoid caecal tissues, studded with multiple eosinophilic granulomas around Schistosoma eggs containing miracidium surrounded by numerous eosinophils. G: Carcinoid tumors composed of a monotonus population of cells arranged in a variety of architectural patterns, including nested (insular), trabecular, acinar, and tubular(x100). H: Tumor stained with Chromogranin A antibody using peroxidase-conjugate and DAB chromogen. Note cytoplasmic staining of tumor cells $(\mathrm{x} 200)$. I: Low grade appendiceal mucinous tumor with serrated gland architecture (x200). J: Section showed appendix muscle layer containing a granuloma with a multinucleated giant cell (x200), Crhon's disease. K: Actinomycosis sections showed involvement of appendix wall by inflammatory reaction featuring plenty of neutrophils with mucosal ulceration, Filamentous bacteria masses within mucosa surrounded by suppurative inflammation. 


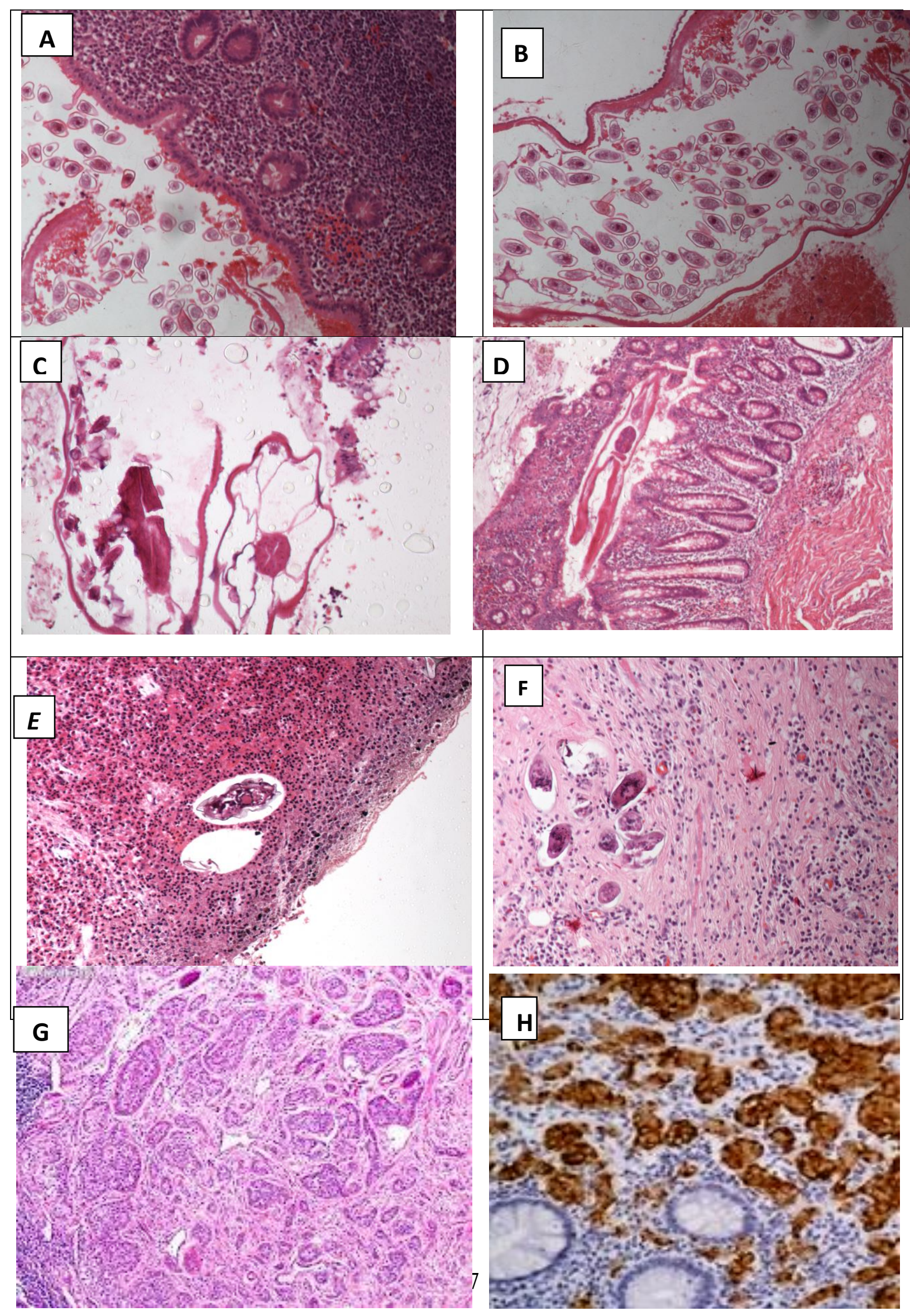



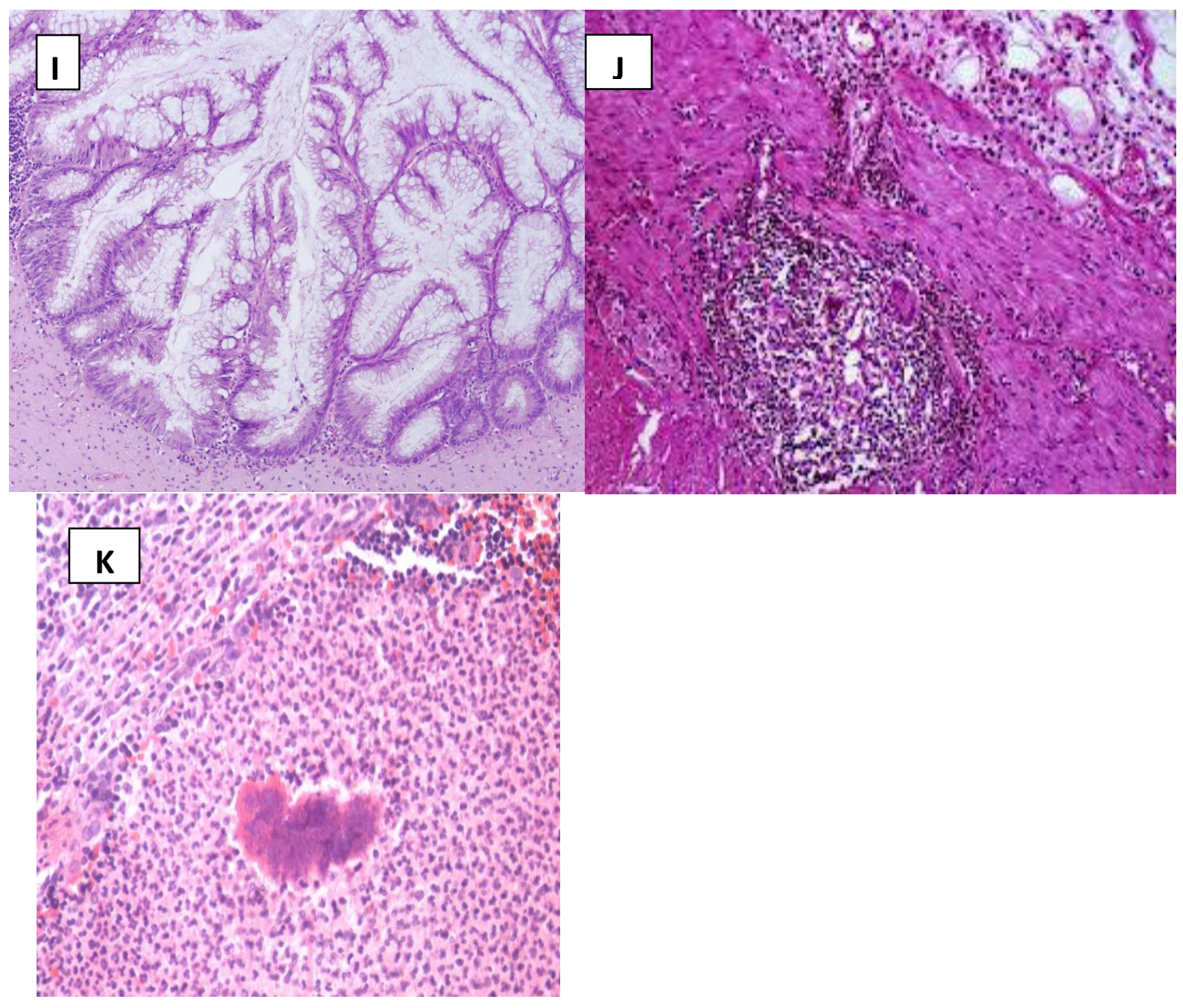

Table 3: Distribution of histopathological types of appendices according to sex of patients

\begin{tabular}{|l|c|c|c|c|c|c|}
\hline \multirow{2}{*}{\multicolumn{1}{c|}{ Histopathological type }} & \multicolumn{6}{|c|}{ Sex of patient } \\
\cline { 2 - 7 } & \multicolumn{3}{|c|}{ Count } & \multicolumn{3}{c|}{ Percent } \\
\cline { 2 - 7 } & Female & Male & Total & Female & Male & Total \\
\hline Acute suppurative appendicitis & 549 & 896 & 1445 & $35.7 \%$ & $58.3 \%$ & $94.1 \%$ \\
\hline Chronic appendicitis & 23 & 24 & 47 & $1.5 \%$ & $1.6 \%$ & $3.1 \%$ \\
\hline Normal Appendix & 17 & 13 & 30 & $1.1 \%$ & $0.8 \%$ & $2.0 \%$ \\
\hline Parasitic & 3 & 3 & 6 & $0.2 \%$ & $0.2 \%$ & $0.4 \%$ \\
\hline Tumor & 2 & 2 & 4 & $0.1 \%$ & $0.1 \%$ & $0.3 \%$ \\
\hline T.B & 3 & 0 & 3 & $0.2 \%$ & $0.0 \%$ & $0.2 \%$ \\
\hline Actinomycosis & 1 & 0 & 1 & $0.1 \%$ & $0.0 \%$ & $0.1 \%$ \\
\hline Total & 598 & 938 & 1536 & $38.9 \%$ & $61.1 \%$ & $100.0 \%$ \\
\hline
\end{tabular}

